\title{
The effects of divided attention at study and test on false recognition: A comparison of DRM and categorized lists
}

\author{
Lauren M. Knott and Stephen A. Dewhurst \\ Lancaster University, Lancaster, England
}

\begin{abstract}
Three experiments investigated the effects of divided attention at encoding and retrieval on false recognition. In Experiment 1, participants studied word lists in either full or divided attention (random number generation) conditions and then took part in a recognition test with full attention. In Experiment 2, after studying word lists with full attention, participants carried out a recognition test with either full or divided attention. Experiment 3 manipulated attention at both study and test. We also compared Deese/Roediger-McDermott (DRM) and categorized lists, due to recent claims regarding the locus of false memories produced by such lists (Smith, Gerkens, Pierce, \& Choi, 2002). With both list types, false "remember" responses were reduced by divided attention at encoding and increased by divided attention at retrieval. The findings suggest that the production of false memories occurs as a result of the generation of associates at encoding and failures of source monitoring retrieval. Crucially, this is true for both DRM and categorized lists.
\end{abstract}

Both the Deese/Roediger-McDermott (DRM) procedure (Deese, 1959; Roediger \& McDermott, 1995) and the category repetition procedure (Dewhurst \& Anderson, 1999; Dewhurst \& Farrand, 2004; Seamon, Luo, Schlegel, Greene, \& Goldenberg, 2000) provide a means by which false memories can be created and studied in the laboratory. In both procedures, participants are presented with short word lists containing either semantic associates of a word not presented or members of semantic categories with highly typical exemplars not presented. Research has shown that the DRM and category repetition procedures both lead to false recognition errors that under some conditions are indistinguishable from correct recognition. This can be seen from research investigating participants' subjective experience of false recognition using the remember/know procedure (Gardiner, 1988; Tulving, 1985). Falsely recognized items are frequently labeled as remember $(\mathrm{R})$ responses, based on conscious recollection, as opposed to know $(\mathrm{K})$ responses, based on familiarity.

Findings from both DRM and category repetition studies have been explained in terms of an activation-monitoring account developed by Roediger and McDermott (1995) based in part on Underwood's (1965) implicit-associativeresponse theory. Roediger and McDermott proposed that false recognition occurs because participants generate associates of the studied items. For example, a participant may see the word hot at the encoding phase and spontaneously think of the associate cold. When presented with the lure cold at test, participants falsely label it as old. Roediger and McDermott claimed that the critical lures are activated at study and falsely recognized at test due to the failure to distinguish between internally generated and externally presented events (see Johnson, Hashtroudi, \& Lindsay, 1993).

A study by Smith, Gerkens, Pierce, and Choi (2002) compared the memory illusions created by the DRM and category repetition procedures. Smith et al. investigated whether the memory illusions are caused by processes that occur at encoding or by processes that occur at retrieval. They compared two hypotheses that support either an encoding or a retrieval explanation for the false memory effect. The Kirkpatrick (1894) hypothesis, based on an early description of the effects of semantically related materials on false memory, states that false memories occur because of associative processes that take place when words are encoded. Smith et al. suggest that false memories created by DRM lists (which they term "associative lists") support the Kirkpatrick hypothesis. In contrast, the Deese hypothesis indicates that, since the recall or recognition of words at test activates associations to nonpresented items, false memory effects are due to associative processes occurring at retrieval. Smith et al. suggested that categorized lists produce false memories in line with the Deese hypothesis. Thus, according to Smith et al., false memories in the DRM procedure are caused primarily by associative processes at encoding, whereas false memories in the category repetition procedure are caused primarily by associative processes at retrieval.

Smith et al. (2002) reported a series of experiments comparing DRM and categorized lists. In their Experiment 1, participants gave free associations to words from both DRM and categorized lists. Smith et al. found that

L.M. Knott, l.cooper1@lancaster.ac.uk 
critical lures from DRM lists were given as responses in free association at a significantly higher rate than critical lures from categorically organized lists (critical lures from categorized lists consisted of the most typical member of a category). In Experiments 2 and 3, Smith et al. found that DRM lists, unlike categorized lists, produced indirect priming effects in word stem completion tests. Smith et al. argued that when participants study categorized lists, they do not experience critical nonpresented category items as associative responses. However, critical lures from DRM lists have higher backward associative strength than those from categorized lists and are thus more likely to be activated by the associative responses that lead to indirect priming effects.

Smith et al.'s (2002) final experiment examined the effects of semantic confusion at test on false memory using categorized lists. In a word stem completion task, participants were given either incidental instructions at test (complete word stems with the first word that comes to mind) or intentional instructions (complete word stems with studied words whenever possible). Results showed that an indirect priming effect occurred when participants were given intentional instructions; thus, the instruction to use studied words increased the likelihood that participants would use nonpresented critical words on the stem completion test. Smith et al. argued that the increase in false recognition following intentional instructions indicates that false memories produced by the category repetition procedure result from semantic confusions at test. In contrast, the indirect priming effects found with associative lists in their previous experiments indicate that false memories produced by the DRM procedure result from semantic associations at study.

Smith et al. (2002) suggested that their findings have important implications for false memory research that seeks to separate study and test effects. Categorized lists appear to elicit false memories at the time of testing without the impact of study effects found using the DRM procedure, and vice versa. However, this claim is incompatible with a number of previous findings; for example, Dewhurst, Barry, and Holmes (2005) found, using categorized lists, that the incidence of false R responses increased and decreased in line with the opportunity to generate associates at study. Specifically, the number of false $\mathrm{R}$ responses decreased when attention was divided at study and increased when participants were explicitly instructed to make associations at study. Pierce, Gallo, Weiss, and Schacter (2005) also found an equivalent modality effect using both DRM and categorized lists. Pierce et al. argued that participants were better able to use test-based monitoring processes to reduce false memories after visual rather than auditory study, and that this occurred for both list types.

The present study was designed on the basis of these findings, to examine further the role of encoding and retrieval processes in false recognition, using both DRM and categorized lists. Smith et al. (2002) found that false memories in the category repetition procedure were affected by a manipulation of test instructions, indicating a possible role for retrieval in the creation of false memories. A number of other studies have shown that experi- mental manipulations at test can increase false memories; for example, Heit, Brockdorff, and Lamberts (2004) investigated the time course of false recognition for DRM items using the response signal technique. Their results indicated that the false recognition of critical lures increased with early response signals and decreased with late response signals. They argued that false recognition occurred as a result of early automatic processing, whereas later responses allowed for more strategic processing that reduced false memories.

Dividing attention at test has also been used to manipulate recognition responses. Retrieval processes were previously believed to be relatively automatic and resistant to manipulations of attention (Craik, Govoni, NavehBenjamin, \& Anderson, 1996); however, more recent research has demonstrated that retrieval processes can be disrupted by attentionally demanding secondary tasks. For example, Fernandes and Moscovitch (2000) investigated the effects of concurrent tasks (e.g., recognition of words; word and digit monitoring) on an oral free-recall task. Divided attention (DA) at retrieval, using word-based concurrent tasks, produced relatively large interference effects, compared with the digit-monitoring task. They argued that interference at retrieval only occurred when the memory and concurrent tasks competed for access to word-specific representational systems (see Fernandes \& Moscovitch, 2002, for similar results). Hicks and Marsh (2000) investigated the effects of random number/letter generation and auditory serial addition tasks during recognition. They found that concurrent tasks selectively impaired items that required consciously controlled processing, leaving unaffected those items that relied on automatic processes. More recently, Knott and Dewhurst (2007) investigated the effects of DA at retrieval on R and $\mathrm{K}$ responses in recognition memory (Gardiner, 1988; Tulving, 1985). They found that DA at retrieval reduced familiarity-based recognition as measured by $\mathrm{K}$ responses but did not affect recollection as measured by $\mathrm{R}$ responses. Knott and Dewhurst also found evidence that DA at test increased false $\mathrm{R}$ responses, although overall levels of false recognition were relatively low.

In the present study, we investigated the effects of DA at encoding and retrieval on false recognition, using both the DRM and category repetition procedures. Random number generation (RNG) was chosen as the DA task, since previous research has shown that it places heavy demands on attentional resources at both encoding (Baddeley, Emslie, Kolodny, \& Duncan, 1998; Dewhurst et al., 2005) and retrieval (Hicks \& Marsh, 2000). Effects of divided attention were investigated separately at the encoding phase in Experiment 1 and at the retrieval phase in Experiment 2. In the final experiment, attention was manipulated at both encoding and retrieval.

The remember-know procedure (Gardiner, 1988; Tulving, 1985) was used at test in order to measure the subjective experience of true and false recognition. There have been a number of recent modifications to the remember-know procedure. In Tulving's original recognition study, participants were required to indicate which items they confidently recognized and then to assign an 
R or K response to each recognized item. Similarly, Dewhurst and Conway (1994) introduced a procedure whereby participants were asked to make a timed old/new decision followed by an untimed R/K decision for each item. Eldridge, Sarfatti, and Knowlton (2002) termed this a twostep procedure. Other researchers have made variations to this procedure to allow for only a single judgment. For example, participants have been instructed to answer R, K, or new in a one-step procedure (Brewer, Zhao, Desmond, Glover, \& Gabrieli, 1998; Yonelinas \& Jacoby, 1995). The purpose of the one-step procedure (Eldridge et al., 2002) is to eliminate any initial recognition judgments made prior to the $\mathrm{R} / \mathrm{K}$ decision. Any additional remembering that occurs in the brief interval between making the old/ new decision and the $\mathrm{R} / \mathrm{K}$ response could provide an opportunity to report a response that may differ from that given at the time of initial recognition (Gardiner, Konstantinou, Karayianni, \& Gregg, 2005). We chose to adopt the one-step procedure on the basis of this argument.

Several studies have compared the one-step and twostep remember-know procedures (e.g. Eldridge et al., 2002; Gardiner et al., 2005; Hicks \& Marsh, 1999). These studies have shown that participants in the one-step procedure adopt a more lenient response criterion and make more correct and false $\mathrm{K}$ responses than do participants in the two-step procedure. However, when a guess (G) response is added to the one-step procedure, the reduced accuracy associated with $\mathrm{K}$ responses transfers to guesses, thus allowing participants to discriminate more reliably between old and new items when making a $\mathrm{K}$ response (Eldridge et al., 2002; Gardiner, Ramponi, \& RichardsonKlavehn, 2002). Gardiner, Java, and Richardson-Klavehn (1996) argued that when guessing is not explicitly included as a response option, participants use $\mathrm{K}$ responses as a proxy for guesses. Moreover, because participants do not reveal any ability to distinguish between studied and unstudied items when making a guess response, guessing, unlike knowing, shows no evidence of memory for the experimental episode. Indeed, as Gardiner and Conway (1999) discussed, G responses often have negative discriminability in that false alarms exceed hits.

The interpretation of $G$ responses can also vary, depending on whether a one-step or a two-step procedure is used. A G response in the two-step procedure can be seen as a low-confidence hit, because participants have already labeled the item as old in the preceding old/new decision. In contrast, $\mathrm{G}$ responses in the one-step procedure may be inflated by items that would have been rejected as new, if the $\mathrm{G}$ option had not been available. This is supported by the finding that the more lenient response criterion observed in the one-step procedure transfers to $G$ responses when that option is available. A G option was therefore included in the following experiments in order to increase the accuracy of $\mathrm{K}$ judgments. However, in light of the above arguments, $\mathrm{G}$ responses were not included in the statistical analyses, either separately or in combination with $\mathrm{R}$ and $\mathrm{K}$ responses. The instructions we gave to participants regarding $\mathrm{G}$ responses also emphasized that this option was to be used in cases in which they were uncertain whether or not a test item had appeared at study.
To summarize, the aims of the present study were (1) to compare the effects of DA at encoding and DA at retrieval on correct and false recognition and (2) to compare the effects of DA on DRM and categorized lists in order to test the views of Smith et al. (2002) regarding the different loci of the false memories produced by such lists.

\section{EXPERIMENT 1}

\section{Method}

Participants. Forty-eight students from Lancaster University took part in Experiment 1. All were native English speakers (age range, $18-28$ years). They were tested individually and were paid $£ 4$ each for their participation. Participants were randomly allocated to either the DRM or the categorized list condition.

Design and Stimuli. The experiment followed a 2 (attention: full vs. divided) $\times 2$ (list type: DRM vs. category) mixed factorial design with repeated measures on the first factor. For the DRM stimuli, 24 lists were taken from Stadler, Roediger, and McDermott (1999). Each list contained 10 associates of 2 critical lures. The first critical lure was the original lure identified by Stadler et al. for each list, and the second was randomly chosen from the top half of each list. The 24 lists were randomly divided into two sets of 12 , to make 2 study lists. The order of presentation of the words in each list was held constant, with the highest associate presented first, followed by a further nine words in descending order of associative strength. There were two recognition tests, each consisting of 72 randomly ordered words. The first recognition test featured items taken from the first set of 12 study lists, and the second test featured items taken from the second set of 12 study lists. Each recognition test included 24 studied items (one high-associated item and one low-associated item chosen randomly from each study list), 24 nonpresented critical lures, and 24 additional unrelated words taken from the unused lists in Stadler et al. Full counterbalancing was observed with respect to study/test conditions, as well as the order in which the participant was required to carry out each condition. Twenty-four categorized lists were also used, with each list containing 10 studied words and 2 critical lures. Categorized lists were taken from Van Overschelde, Rawson, and Dunlosky (2004) and compiled in the same fashion as DRM stimuli. List type was manipulated between participants, so that each participant studied 2 lists of the same type.

Procedure. Items from the study and test phases were presented on an Apple Macintosh computer. Each study item appeared on the screen for $1 \mathrm{sec}$, with an interstimulus interval of $1 \mathrm{sec}$. Due to the repeated measures design of the experiment, participants were required to study two word lists, each followed by a separate recognition test; therefore, participants carried out two study-test experiments, one with full attention and one with divided attention. In the full attention condition, participants were instructed to read the words silently in preparation for a recognition test. In the divided attention condition, participants were additionally instructed to randomly generate numbers between 1 and 20 in time to a digital metronome every $750 \mathrm{msec}$ throughout the study phase. For the random number generation (RNG) task, participants were given a description of what constituted randomness: They were told that it would be like simulating the rolling of a die, in that each side of the die is equally likely to be selected with every roll, and each roll is independent of the preceding ones. It was also noted that items in a set of generated numbers should not have any obvious relationship to one another (e.g., familiar sequences or counting in increments). The need to maintain the speed and the randomness of their number generating throughout the list presentation was also emphasized. Following each study phase, participants were given a 10-min nonverbal distractor task before proceeding with the recognition test.

A one-step remember/know procedure was adapted from Eldridge et al. (2002). Participants were asked to make an R, K, G, or new response for each item presented on the screen. R, K, and $\mathrm{G}$ responses were made by pressing the appropriately marked keys, and 
new decisions were indicated by making no response and waiting $5 \mathrm{sec}$ for the next item to appear. Instructions for $\mathrm{R}$ and $\mathrm{K}$ responses were taken from Eldridge et al. Briefly, participants were instructed to make an $\mathrm{R}$ response if they consciously recollected some aspect of a word's study presentation, and to make a $\mathrm{K}$ response if a word was familiar but they recalled no contextual information. The instructions for $\mathrm{G}$ response differed from those used by Eldridge et al., in that participants were told to use this response option if they did not recognize the item but could not confidently reject it. Participants were instructed to make a new response if they were confident the word had not been presented at study. After completing the first recognition test, participants were given a 10 -min nonverbal intervening task before being presented with the second study list followed by the second recognition test.

\section{Results and Discussion}

Overall recognition scores $(\mathrm{R}+\mathrm{K})$ and separate $\mathrm{R}$ and $\mathrm{K}$ responses to studied items, critical lures, and unrelated lures were analyzed in separate 2 (attention: full vs. divided) $\times 2$ (list type: DRM vs. category) mixed model ANOVAs. Alpha was set at .05 for all analyses. G responses were not included in the analyses for the reasons discussed above, but their means are displayed in the tables. Table 1 shows the mean proportions of correct and false $\mathrm{R}, \mathrm{K}$, and $\mathrm{G}$ responses and of overall studied items and false alarms for DRM and categorized lists in full and divided attention conditions.

Overall recognition. Analysis revealed a significant main effect of attention, with overall recognition greater in the full attention than in the divided attention condition $\left[F(1,46)=228.78, M S_{\mathrm{e}}=12.60\right]$. There was no main effect of list type $(F<1)$ and no interaction $(F<1)$. Analysis of total false alarms to critical lures revealed a significant main effect of attention, whereby divided attention reduced false recognition $\left[F(1,46)=8.86, M S_{\mathrm{e}}=7.15\right]$. The main effect of list type was marginally significant $\left[F(1,46)=3.67, M S_{\mathrm{e}}=31.91, p<.06\right]$. These effects were qualified by a significant attention $\times$ list type interaction $\left[F(1,46)=4.57, M S_{e}=7.15\right]$. Further analysis revealed that the false recognition of critical lures from DRM lists was significantly reduced by divided attention $\left[F(1,23)=10.55, M S_{\mathrm{e}}=8.87\right]$. However, there was no significant difference for categorized lists $(F<1)$. Analysis of false alarms to unrelated items revealed a significant main effect of attention $\left[F(1,46)=16.53, M S_{\mathrm{e}}=3.93\right]$, with false alarms increasing under divided attention conditions. The main effect of list type was also significant, with more false alarms occurring with DRM lists than with categorized lists $\left[F(1,46)=5.33, M S_{\mathrm{e}}=18.39\right]$. The interaction was not significant $(F<2)$.

Signal detection measures. To facilitate comparisons across lists and attention at encoding, we analyzed discrimination and response bias scores. We used the Snodgrass and Corwin (1988) correction for signal detection theory (SDT) measures, whereby 0.5 was added to hit and false alarm rates and the corrected score was divided by $N+1$. This was used in order to prevent values of 1.0 and 0 . The Snodgrass and Corwin correction was conducted for SDT measures across all three experiments. For discriminability $\left(d^{\prime}\right)$, larger values indicate better memory performance, and for criterion value $(C)$, values greater than 0 represent a conservative bias and less than 0 represents a liberal bias. The calculation of $d^{\prime}$ and $C$ for critical lures and hits used the common false alarm rate for unrelated lures. The results of $d^{\prime}$ and $C$ are summarized in Table 2. Signal detection measures for hits and critical lures were analyzed in separate 2 (list type) $\times 2$ (attention) mixed model ANOVAs. As expected, the analysis of $d^{\prime}$ for hits revealed a significant main effect of attention, whereby discriminability was better with FA than with DA $\left[F(1,46)=162.71, M S_{\mathrm{e}}=0.68\right]$. The main effect of list type was also significant: Discriminability was better for categorized lists than for DRM lists $[F(1,46)=12.00$, $\left.M S_{\mathrm{e}}=0.52\right]$. Crucially, however, the attention $\times$ list type interaction was not significant $(F<3)$. For critical lures, discriminability was also higher for items encoded under full rather than divided attention $\left[F(1,46)=35.61, M S_{\mathrm{e}}=\right.$ $0.06]$. However, there was no significant main effect of list type $(F<1)$ or interaction $(F<1)$.

Analysis of the criterion $C$ revealed a more conservative bias for items encoded in DA than for those in FA $\left[F(1,46)=24.47, M S_{\mathrm{e}}=0.08\right]$. There was no reliable effect of list type $(F<2)$ or interaction $(F<1)$. For critical lures there was no reliable effect of attention; however, there was a significant effect of list type $\left[F(1,46)=6.28, M S_{\mathrm{e}}=\right.$ $0.42]$, whereby responses were more liberal for DRM than

Table 1

Mean Proportions for Responses to Targets, Critical Lures, and Unrelated Lures Under Full and Divided Attention Conditions at Encoding

\begin{tabular}{|c|c|c|c|c|c|c|c|c|c|c|c|c|}
\hline \multirow[b]{3}{*}{ Attention } & \multicolumn{6}{|c|}{ DRM Lists } & \multicolumn{6}{|c|}{ Categorized Lists } \\
\hline & \multicolumn{4}{|c|}{$\begin{array}{c}\text { Critical } \\
\text { Lures }\end{array}$} & \multicolumn{2}{|c|}{ Unrelated } & \multicolumn{4}{|c|}{$\begin{array}{c}\text { Critical } \\
\text { Lures }\end{array}$} & \multicolumn{2}{|c|}{ Unrelated } \\
\hline & $M$ & $S E$ & $M$ & $S E$ & $M$ & $\overline{S E}$ & $M$ & $S E$ & $M$ & $S E$ & $M$ & $S E$ \\
\hline \multicolumn{13}{|l|}{ Full } \\
\hline Old & .74 & .02 & .46 & .04 & .15 & .02 & .79 & .02 & .31 & .04 & .05 & .02 \\
\hline $\mathrm{R}$ & .58 & .03 & .25 & .04 & .05 & .02 & .58 & .04 & .14 & .02 & .01 & .00 \\
\hline K & .17 & .02 & .20 & .02 & .11 & .02 & .21 & .03 & .18 & .02 & .03 & .01 \\
\hline G & .10 & .01 & .19 & .03 & .18 & .03 & .11 & .01 & .27 & .02 & .14 & .04 \\
\hline \multicolumn{13}{|l|}{ Divided } \\
\hline Old & .43 & .04 & .34 & .04 & .20 & .03 & .45 & .02 & .30 & .04 & .14 & .03 \\
\hline $\mathrm{R}$ & .20 & .04 & .15 & .03 & .06 & .02 & .24 & .04 & .09 & .02 & .03 & .01 \\
\hline K & .23 & .03 & .20 & .02 & .14 & .02 & .21 & .02 & .21 & .03 & .11 & .02 \\
\hline $\mathrm{G}$ & .25 & .03 & .28 & .04 & .27 & .03 & .23 & .02 & .24 & .02 & .24 & .03 \\
\hline
\end{tabular}

Note-R, remember; K, know; G, guess. 
Table 2

Signal Detection Measures of Discriminability $\left(d^{\prime}\right)$ and

Bias $(C)$ for Studied Items and Critical Lures in Experiments 1 and 2

\begin{tabular}{|c|c|c|c|c|c|c|c|c|}
\hline \multirow[b]{3}{*}{ Attention } & \multicolumn{4}{|c|}{ DRM Lists } & \multicolumn{4}{|c|}{ Categorized Lists } \\
\hline & \multicolumn{2}{|c|}{$d^{\prime}$} & \multicolumn{2}{|c|}{$C$} & \multicolumn{2}{|c|}{$d^{\prime}$} & \multicolumn{2}{|c|}{$C$} \\
\hline & Studied & Lures & Studied & Lures & Studied & Lures & Studied & Lures \\
\hline \multicolumn{9}{|c|}{ Experiment 1} \\
\hline Full & 1.82 & 1.02 & 0.24 & 0.64 & 2.49 & 1.19 & 0.43 & 1.08 \\
\hline Divided & 0.72 & 0.53 & 0.59 & 0.68 & 1.06 & 0.60 & 0.67 & 0.90 \\
\hline \multicolumn{9}{|c|}{ Experiment 2} \\
\hline Full & 1.99 & 0.85 & 0.39 & 0.96 & 2.08 & 0.84 & 0.34 & 0.95 \\
\hline Divided & 1.85 & 0.91 & 0.36 & 0.83 & 1.96 & 0.98 & 0.30 & 0.79 \\
\hline
\end{tabular}

for category words. This indicates a more general willingness to label DRM words as old. Finally, a significant attention $\times$ list type interaction $\left[F(1,46)=5.14, M S_{\mathrm{e}}=\right.$ $0.06]$ revealed that for category words DA produced a more liberal response bias than did FA $\left[F(1,23)=7.12, M S_{\mathrm{e}}=\right.$ $0.06]$. The same was not true of DRM words $(F<1)$.

Remember and know responses. The analysis of correct $\mathrm{R}$ responses revealed a significant main effect of attention, whereby recognition was greater in the FA than in the DA condition $\left[F(1,46)=139.18, M S_{\mathrm{e}}=12.77\right]$. Neither the main effect of list type nor the interaction was significant (both $F \mathbf{s}<1$ ). A similar analysis of false alarms to critical lures revealed that DA significantly reduced the number of false $\mathrm{R}$ responses $[F(1,46)=18.13$, $\left.M S_{\mathrm{e}}=4.76\right]$. The main effect of list type was significant $\left[F(1,46)=5.98, M S_{\mathrm{e}}=17.06\right]$, indicating that $\mathrm{R}$ responses to critical lures were significantly higher in DRM lists than in categorized lists. Crucially, however, the attention $\times$ list type interaction was not significant $(F<1)$. The false recognition of unrelated lures was low, but significantly more false $\mathrm{R}$ responses to unrelated lures were made in the DRM than in the categorized list condition $\left[F(1,46)=5.46, M S_{\mathrm{e}}=3.37\right]$. The effect of attention and the interaction with list type were not significant.

The analysis of correct $\mathrm{K}$ responses revealed no significant main effect for attention $(F<2)$ or list type $(F<1)$ and no significant attention $\times$ list type interaction $[F(1,46)=$ $2.24, p=.14]$. A similar analysis of critical lures again revealed that $\mathrm{K}$ responses were not affected by attention or list type (both $F \mathrm{~s}<1$ ), nor was there a significant interaction $(F<1)$. Analysis of unrelated lures revealed a significant main effect of attention whereby more false $\mathrm{K}$ responses were made in divided than in full attention conditions $\left[F(1,46)=18.74, M S_{\mathrm{e}}=2.07\right]$. The main effect of list type was not significant $\left[F(1,46)=3.27, M S_{\mathrm{e}}=9.65, p=.07\right]$, nor was the interaction $[F(1,46)=3.67, p=.06]$.

Overall recognition scores revealed that divided attention at study significantly increased false alarms to critical lures for DRM lists but had no effect on categorized lists. This initially supports claims, made by Smith et al. (2002), that false memories occur at encoding for DRM but not at encoding for categorized lists. However, further $d^{\prime}$ and $C$ analyses were conducted as a result of a large proportion of unrelated false alarms for DRM items. Analysis of discriminability and response bias for studied items revealed an effect of attention but no interaction between list type and attention. Analyses for critical lures indicate that the effects of DA at study are similar for both DRM and categorized lists.

In the separate analyses of $\mathrm{R}$ and $\mathrm{K}$ responses, Experiment 1 showed that DA at study reduced both correct and false R responses to DRM and categorized lists. This is consistent with the findings from Dewhurst, Barry, Swannell, Holmes, and Bathurst (2007) and from Dewhurst et al. (2005): Both studies found the same pattern of results using DRM and categorized lists, respectively. Experiment 1 also showed that DA at study had no effect on $\mathrm{K}$ responses. This is a robust finding also reported by Dewhurst et al. (2007), who argued that $\mathrm{K}$ responses are unaffected by DA, because they are the result of automatic spreading activation processes that are not under conscious control (see Dewhurst et al., 2005, for further discussion).

In contrast to claims made by Smith et al. (2002), the effects of DA at encoding were the same for DRM and categorized lists. Although more false $\mathrm{R}$ responses were made in the DRM than in the categorized lists (see Pierce et al., 2005 , for similar findings), DA led to parallel reductions in false $\mathrm{R}$ responses. These findings suggest that levels of false $\mathrm{R}$ responses in both DRM and categorized lists are influenced by processes that occur at encoding.

\section{EXPERIMENT 2}

Experiment 1 showed that false $\mathrm{R}$ responses produced by both the DRM and category repetition procedures are reduced by DA at study. Experiment 2 investigated the effect of DA at test on DRM and categorized lists. The activation-monitoring account implicates retrieval processes in false memory, with the failure to monitor the source of memory traces leading to the false recognition of generated items (Roediger \& McDermott, 1995). Based on the claims of Smith et al. (2002), manipulations of retrieval processes should not affect the false recognition of critical lures from DRM lists; however, manipulation of retrieval processes should affect the false recognition of critical lures from categorized lists.

\section{Method}

The method was the same as that used in Experiment 1, except for the following modifications. A new group of 54 undergraduates took part in the experiment for course credit. Participants again took part in two study phases, each phase followed by a separate 
recognition test. Study lists were presented in full attention conditions, and participants were instructed to read each word silently in preparation for a recognition test. Attention was manipulated at test. In the control condition, participants made $\mathrm{R} / \mathrm{K} / \mathrm{G}$ or new decisions with full attention. In the DA condition, participants were instructed to perform the RNG task throughout the recognition test. Again, participants were randomly allocated either to the DRM list or to the categorized list condition.

\section{Results and Discussion}

Total recognition scores and separate $\mathrm{R}$ and $\mathrm{K}$ responses to studied items, critical lures, and unrelated lures were analyzed in separate 2 (attention: full vs. divided) $\times 2$ (list type: DRM vs. category) mixed model ANOVAs. Table 3 shows the mean proportions of correct and false scores, and separate $\mathrm{R}, \mathrm{K}$, and $\mathrm{G}$ responses for DRM and categorized lists in both attention conditions.

Overall recognition. Analysis revealed no significant main effects of attention, list type, or interaction (all $\left.F_{\mathrm{S}}<1\right)$. In contrast, DA at test significantly increased false alarms $\left[F(1,52)=11.69, M S_{\mathrm{e}}=5.20\right]$. Neither the main effect of list type nor the interaction was significant (both $F \mathrm{~s}<1$ ). False alarms to unrelated items were low, with no significant effects of attention or list type (both $F$ s $<1)$ or interaction $(F<1)$.

Signal detection measures. As in Experiment 1, signal detection measures were analyzed for items recognized as old and false alarms to critical lures to compare memory performance and criterion bias across list types and attention. The results for $d^{\prime}$ and $C$ are summarized in the lower section of Table 2. The $d^{\prime}$ and $C$ scores were analyzed in separate 2 (attention: full vs. divided) $\times 2$ (list type: DRM vs. category) mixed model ANOVAs. For discriminability, all results were nonsignificant (all $F_{\mathrm{S}}<1$ ). This indicates that for overall recognition scores and false alarms, discriminability was not affected by DA or list type. These results were expected, since the effects of DA at retrieval only appear when $\mathrm{R}$ and $\mathrm{K}$ responses are analyzed separately (Knott \& Dewhurst, 2007). Analysis of criterion $C$ for correct recognition showed no significant main effects of attention $(F<1)$ and list type $(F<1)$. However, analysis of criterion for critical lures indicated a significant main effect of attention $[F(1,52)=8.07$, $\left.M S_{\mathrm{e}}=0.07\right]$, whereby DA produced a more conservative bias toward critical lures. The main effect of list type and the interaction remained nonsignificant.

$R$ and $K$ responses. The analysis of correct $R$ responses produced nonsignificant main effects of attention $(F<3)$ and list type $(F<1)$, and a nonsignificant interaction $(F<1)$. In contrast, divided attention at test significantly increased false $\mathrm{R}$ responses to critical lures $\left[F(1,52)=21.36, M S_{\mathrm{e}}=5.24\right]$. The main effect of list type $(F<1)$ and the interaction $(F<2)$ were not significant. False $\mathrm{R}$ responses to unrelated lures were low, but were significantly increased by divided attention $[F(1,52)=$ $\left.16.85, M S_{e}=1.49\right]$. Neither the main effect of list type $(F<1)$ nor the interaction $(F<3)$ was significant.

Similar analyses of $\mathrm{K}$ responses revealed a significant main effect of attention for hits, whereby more correct $\mathrm{K}$ responses were made under full rather than divided attention conditions $\left[F(1,52)=12.92, M S_{\mathrm{e}}=3.82\right]$. Neither the main effect of list type $(F<1)$ nor the interaction $(F<1)$ was significant. Analysis of false $\mathrm{K}$ responses to both critical and unrelated lures produced no significant effects or interactions (all $F_{\mathrm{S}}<2$ ).

A final cross-experimental analysis of the data from Experiments 1 and 2 investigated whether the effect of DA was greater when implemented at study or at test. Previous research has established that DA has a greater effect on correct recognition at study than at test (Craik et al., 1996); however, there has been little research investigating whether DA has a greater effect on false recognition at study or at test. Therefore, separate 2 (attention: full vs. divided) $\times 2$ (DA location: test vs. study) $\times 2$ (list type: DRM vs. category) mixed model ANOVAs were conducted on $\mathrm{R}$ and $\mathrm{K}$ responses to targets and critical lures. In all analyses, DA location had no effect on list type, indicating that the effect of DA was equivalent for DRM and categorized lists. For correct $\mathrm{R}$ responses, the main effects of attention $\left[F(1,98)=65.09, M S_{\mathrm{e}}=11.23\right]$ and DA location $\left[F(1,98)=26.09, M S_{\mathrm{e}}=2.04\right]$ were significant. These effects were qualified by a significant DA $\times$ attention interaction $\left[F(1,98)=104.75, M S_{\mathrm{e}}=11.23\right]$. Analysis of simple main effects indicated that correct $\mathrm{R}$ responses were significantly reduced by DA at study $\left[F(1,46)=139.18, M S_{\mathrm{e}}=12.77\right]$, but were not reliably affected by DA at test. For R responses to critical lures,

Table 3

Mean Proportions for Responses to Targets, Critical Lures, and Unrelated Lures Under Full and Divided Attention Conditions at Retrieval

\begin{tabular}{|c|c|c|c|c|c|c|c|c|c|c|c|c|}
\hline \multirow[b]{3}{*}{ Attention } & \multicolumn{6}{|c|}{ DRM Lists } & \multicolumn{6}{|c|}{ Categorized Lists } \\
\hline & \multicolumn{2}{|c|}{ Studied } & \multicolumn{2}{|c|}{ Critical Lures } & \multicolumn{2}{|c|}{ Unrelated } & \multicolumn{2}{|c|}{ Studied } & \multicolumn{2}{|c|}{ Critical Lures } & \multicolumn{2}{|c|}{ Unrelated } \\
\hline & $M$ & $S E$ & M & $S E$ & $M$ & $S E$ & $M$ & $S E$ & M & $S E$ & $M$ & $S E$ \\
\hline \multicolumn{13}{|l|}{ Full } \\
\hline Old & .71 & .03 & .30 & .03 & .09 & .03 & .75 & .03 & .32 & .03 & .12 & .03 \\
\hline $\mathrm{R}$ & .53 & .03 & .14 & .02 & .02 & .01 & .54 & .03 & .12 & .02 & .02 & .01 \\
\hline $\mathrm{K}$ & .18 & .02 & .16 & .02 & .08 & .02 & .22 & .02 & .20 & .03 & .10 & .03 \\
\hline $\mathrm{G}$ & .13 & .02 & .16 & .02 & .16 & .03 & .10 & .02 & .23 & .03 & .09 & .02 \\
\hline \multicolumn{13}{|l|}{ Divided } \\
\hline Old & .71 & .03 & .36 & .04 & .11 & .02 & .73 & .03 & .32 & .04 & .15 & .02 \\
\hline $\mathrm{R}$ & .57 & .03 & .21 & .03 & .04 & .01 & .58 & .03 & .23 & .03 & .07 & .02 \\
\hline K & .14 & .02 & .15 & .02 & .07 & .01 & .15 & .03 & .16 & .02 & .06 & .01 \\
\hline G & .08 & .01 & .13 & .02 & .14 & .03 & .05 & .01 & .11 & .02 & .08 & .02 \\
\hline
\end{tabular}

Note-R, remember; K, know; G, guess. 
there were no main effects of attention or DA location $(F<1)$. However, the attention $\times \mathrm{DA}$ location interaction was significant $\left[F(1,98)=39.18, M S_{\mathrm{e}}=5.02\right]$. Analysis of simple main effects revealed that false $\mathrm{R}$ responses were significantly reduced by DA at study $[F(1,46)=$ $\left.18.13, M S_{\mathrm{e}}=4.76\right]$, but significantly increased by DA at test $\left[F(1,52)=21.36, M S_{\mathrm{e}}=5.24\right]$.

For correct $\mathrm{K}$ responses, analysis of hits revealed significant main effects of attention $\left[F(1,98)=65.09, M S_{\mathrm{e}}=\right.$ 11.23] and DA location $\left[F(1,98)=26.09, M S_{\mathrm{e}}=26.88\right]$. These were qualified by a significant attention $\times$ DA location interaction $\left[F(1,98)=104.75, M S_{\mathrm{e}}=5.18\right]$. Analysis of simple main effects revealed that correct $\mathrm{K}$ responses were not reliably affected by DA at encoding $(F<2)$, but were significantly reduced by DA at retrieval $[F(1,52)=12.92$, $\left.M S_{\mathrm{e}}=3.82\right]$. For false $\mathrm{K}$ responses to critical lures, neither the main effects nor the interactions reached significance (all $F \mathrm{~s}<1$ ). In conclusion, DA at encoding appears to reduce correct and false recognition; however, DA at retrieval appears to have more selective effects. DA increases false $\mathrm{R}$ responses but decreases correct $\mathrm{K}$ responses. Possible explanations for this are considered in the General Discussion.

In summary, the findings from Experiment 2 show that divided attention at retrieval increased false $\mathrm{R}$ responses to critical lures but had no reliable effect on correct $\mathrm{R}$ responses. In contrast, DA at test reduced correct $\mathrm{K}$ responses but had no reliable effect on false $\mathrm{K}$ responses. It is clear from these results that DA at retrieval has a different effect on false memory than DA at encoding. Specifically, DA at encoding reduces false $\mathrm{R}$ responses, whereas DA at retrieval increases them. Crucially, this pattern occurred for both DRM and categorized lists. The finding that DA at test reduced correct $\mathrm{K}$ responses but not correct $\mathrm{R}$ responses is consistent with the findings of Knott and Dewhurst (2007). They argued that the reduction in $\mathrm{K}$ responses in the DA condition occurred because $\mathrm{K}$ responses rely on consciously controlled decision processes that are disrupted by the secondary task. The finding that correct $\mathrm{R}$ responses are unaffected by the secondary task suggests that they rely on automatic processes that are more resistant to interference. This is considered further in the General Discussion.

\section{EXPERIMENT 3}

Across Experiments 1 and 2, divided attention was manipulated between groups, with attention divided at encoding in Experiment 1 and at retrieval in Experiment 2. The purpose of Experiment 3 was to investigate the effects of DA at both encoding and retrieval using a withingroups design. This allowed us to investigate the effects on false recognition of both impoverished encoding and test conditions. The effects of such impoverished conditions on false memories have not previously been investigated; however, Hicks and Marsh (2000) carried out a similar experiment to investigate recognition accuracy of nouns. Their findings showed that DA at test only had a detrimental effect on items studied in full attention. The present study allowed us to investigate whether the effect of DA at test on false recognition also interacts with manipulations of attention at study. In addition, the within-participants design of Experiment 3 also reduced the potential impact of individual differences. Finally, Experiment 3 investigated performance on the DA task itself, in that measures of randomness were taken before study and then during the encoding and retrieval stages.

\section{Method}

Participants. Forty-eight students from Lancaster University took part in Experiment 3. Participants (age range, 18-26 years) were all native English speakers and had not taken part in either of the previous two experiments. The students were paid $£ 4$ each for their participation.

Design and Stimuli. The experiment followed a 2 (study condition: full vs. divided) $\times 2$ (test condition: full vs. divided) $\times 2$ (list type: DRM vs. category) mixed factorial design with repeated measures on the first two factors. DRM and categorized lists and their respective critical lures were taken from Experiments 1 and 2. Sixteen word lists were used to make up the study phase for both DRM and categorized list conditions. Study lists were divided into four sets. Participants studied two sets in a FA condition and two sets in a DA condition. Due to the within-groups design of this experiment, critical lures and studied items from half the lists studied in DA conditions were tested with DA, and those from the other half were tested with FA. Similarly, critical lures and studied items from half the lists studied in FA conditions were tested in DA, and those from the other half were tested with FA. This allowed for a full crossover of DA and FA conditions at study and test. Full counterbalancing occurred in the order of attention, in which participants were required to carry out the study-test phases, and in the order in which they were required to study the group lists. Participants were randomly allocated to either the DRM list or the categorized list condition.

Procedure. Each study item was presented for $1 \mathrm{sec}$, with a 3 -sec interval between lists. If attention was to be divided in the first half of the study phase, participants were requested to begin the secondary task $5 \mathrm{sec}$ before the initial item appeared on the screen. A fixation point appearing on the screen for $2 \mathrm{sec}$ preceded the onset of the first item. Halfway through the study phase, the program paused and participants were instructed to complete the second half of the study without carrying out the additional secondary task. They were asked to continue by pressing the space bar when they were ready. If participants carried out the first half of the experiment with full attention, when the program paused they were given instructions to carry out the secondary task for the second part of the study. Again, participants were requested to begin the secondary task $5 \mathrm{sec}$ before resuming study.

The recognition test consisted of 32 studied items, 32 lure items, and 32 unrelated items presented in a random order. The remember-know procedure was adopted at test (see Experiment 1 for details). The allocated attention conditions at test followed a similar pattern to that of encoding. Therefore, 12 participants carried out the test with DA followed by FA, and 12 with FA followed by DA, with a pause to signal the halfway mark and the need to change their attention condition.

Baseline performance on the RNG secondary task was measured before participants carried out the study task. For number generation, a measure of randomness (termed RNG) was taken from Evans (1978). RNG values range from 0 to 1 , with lower values indicating more random sequences. Participants' number sequences were recorded with and without the recognition test and analyzed to measure how close they were to simulating a random sequence of numbers in both situations. This allowed for a measure of potential performance trade-offs. RgCalc, a program designed by Towse and Neil (1998), was used to analyze RNG.

\section{Results and Discussion}

In a manner similar to Experiments 1 and 2, overall recognition scores and $\mathrm{R} / \mathrm{K}$ responses were analyzed in separate 2 (attention at study: full vs. divided) $\times 2$ (atten- 
tion at test: full vs. divided) $\times 2$ (list type: category vs. DRM) mixed model ANOVAs, with repeated measures on the first two factors. Mean proportions of recognition accuracy and $\mathrm{R}, \mathrm{K}$, and $\mathrm{G}$ responses are reported by list type and attention condition in Table 4.

Overall recognition. Analysis revealed a significant main effect of attention at study, whereby correct responses were greater in FA than in DA $\left[F(1,48)=52.71, M S_{\mathrm{e}}=\right.$ 3.83]. The main effects of attention of test $(F<2)$ and list type $(F<1)$ were not significant. Surprisingly, the attention at study $\times$ list type interaction was significant $[F(1,48)=$ $\left.6.21, M S_{\mathrm{e}}=3.83\right]$. Further analysis indicated that DA at study significantly reduced hits to DRM words $[F(1,24)=$ $\left.37.39, M S_{\mathrm{e}}=4.88\right]$ with no effect on category words $(F<1)$. For false alarms to critical lures, DA at study increased responses $\left[F(1,48)=53.05, M S_{\mathrm{e}}=2.44\right]$. Neither attention at test nor list type was significant $(F<1)$. However, there was an interaction between the study and test manipulation $\left[F(1,48)=10.80, M S_{\mathrm{e}}=2.60\right]$. Further analysis indicates that with FA at study, DA at test had no effect on critical lure recognition $(F<1)$. However, with DA at study, DA at test increased the recognition of critical lures $[F(1,48)=10.86$, $\left.M S_{\mathrm{e}}=2.12\right]$. This interaction supports the separate effects of DA at study and test from Experiments 1 and 2. Finally, DA at test increased the false alarm rate for unrelated lures $\left[F(1,48)=7.91, M S_{\mathrm{e}}=1.92\right]$, but there was no significant effect of list type or interaction $(F<1)$.

Signal detection measures. Discrimination and response bias scores for correctly recognized items and critical lures are summarized in Table 5. Similarly to the scores for overall recognition, $d^{\prime}$ and $C$ were analyzed in
2 (attention at study) $\times 2$ (attention at test) $\times 2$ (list type) mixed model ANOVAs. The analysis of $d^{\prime}$ for correct responses indicated that both DA at study $[F(1,48)=49.76$, $\left.M S_{\mathrm{e}}=0.46\right]$ and DA at test $\left[F(1,48)=7.71, M S_{\mathrm{e}}=0.57\right]$ reduced discriminability. Although the main effect of list type was not significant, there was an attention at study $\times$ list type interaction $\left[F(1,48)=8.06, M S_{\mathrm{e}}=0.46\right]$. However, further analysis indicated that DA at study significantly reduced discriminability for both $\operatorname{DRM}[F(1,48)=$ $\left.37.00, M S_{\mathrm{e}}=0.60\right]$ and categorized lists $[F(1,48)=13.11$, $\left.M S_{\mathrm{e}}=0.31\right]$. Analysis of $d^{\prime}$ for critical lures revealed similar effects of DA at study $\left[F(1,48)=18.45, M S_{\mathrm{e}}=0.65\right]$, reducing discriminability; however, there was no effect of $\mathrm{DA}$ at test or list type (both $F \mathrm{~s}<2$ ). There was, however, an attention at study $\times$ test interaction $[F(1,48)=9.02$, $\left.M S_{\mathrm{e}}=0.35\right]$. Further analysis indicated that with FA at test, DA at study significantly reduced discriminability $\left[F(1,48)=23.09, M S_{\mathrm{e}}=0.41\right]$, but this effect did not occur with DA at test $(F<1)$.

Analysis of the criterion for recognition of studied items revealed that FA at study caused more liberal responses, whereby participants were more willing to call items old under conditions of FA than under conditions of DA $\left[F(1,48)=49.76, M S_{\mathrm{e}}=0.11\right]$. The main effect of list type and attention at test were not significant (both $\left.F_{\mathrm{S}}<2\right)$. There was a significant attention at study $\times$ list type interaction $\left[F(1,48)=8.09, M S_{\mathrm{e}}=0.11\right]$. Further analysis revealed that for both DRM words $[F(1,48)=$ $\left.37.00, M S_{\mathrm{e}}=0.15\right]$ and category words $[F(1,48)=13.11$, $\left.M S_{\mathrm{e}}=0.08\right]$, response bias was greater in FA. Analysis of critical lures revealed a similar effect of DA at study

Table 4

\begin{tabular}{|c|c|c|c|c|c|c|c|c|c|c|c|c|}
\hline \multirow{4}{*}{$\begin{array}{l}\text { Study } \\
\text { Condition }\end{array}$} & \multicolumn{12}{|c|}{ Test Condition } \\
\hline & \multicolumn{6}{|c|}{ Full Attention } & \multicolumn{6}{|c|}{ Divided Attention } \\
\hline & \multicolumn{2}{|c|}{ Studied } & \multicolumn{2}{|c|}{$\begin{array}{c}\text { Critical } \\
\text { Lures }\end{array}$} & \multicolumn{2}{|c|}{ Unrelated } & \multicolumn{2}{|c|}{ Studied } & \multicolumn{2}{|c|}{$\begin{array}{c}\text { Critical } \\
\text { Lures }\end{array}$} & \multicolumn{2}{|c|}{ Unrelated } \\
\hline & $M$ & $S E$ & $M$ & $S E$ & $M$ & $S E$ & $M$ & $S E$ & $M$ & $S E$ & $M$ & $S E$ \\
\hline \multicolumn{13}{|c|}{ DRM Lists } \\
\hline Full & & & & & & & & & & & & \\
\hline Old & .80 & .03 & .41 & .06 & .12 & .03 & .70 & .05 & .32 & .03 & .17 & .04 \\
\hline $\mathrm{R}$ & .63 & .04 & .23 & 04 & .03 & .01 & .50 & .06 & .18 & .03 & .09 & .03 \\
\hline K & .17 & .03 & .19 & .03 & .06 & .02 & .20 & .03 & .14 & .03 & .11 & .03 \\
\hline $\mathrm{G}$ & .08 & .02 & .11 & .02 & .17 & .03 & .12 & .03 & .16 & .04 & .15 & .03 \\
\hline \multicolumn{13}{|l|}{ Divided } \\
\hline Old & .39 & .06 & .21 & .05 & .12 & .03 & .44 & .04 & .36 & .06 & .17 & .04 \\
\hline $\mathrm{R}$ & .15 & .03 & .03 & .01 & .03 & .01 & .25 & .04 & .20 & .04 & .09 & .03 \\
\hline $\mathrm{K}$ & .24 & .05 & .18 & .04 & .06 & .02 & .19 & .03 & .16 & .03 & .11 & .03 \\
\hline G & .17 & .03 & .17 & .03 & .17 & .03 & .18 & .03 & .13 & .03 & .15 & .03 \\
\hline \multicolumn{13}{|c|}{ Categorized Lists } \\
\hline Full & & & & & & & & & & & & \\
\hline Old & .71 & .03 & .52 & .05 & .13 & .03 & .66 & .03 & .48 & .04 & .18 & .03 \\
\hline $\mathrm{R}$ & .50 & .04 & .22 & .04 & .02 & .01 & .50 & .04 & .27 & .05 & .07 & .02 \\
\hline $\mathrm{K}$ & .21 & .04 & .30 & .05 & .11 & .03 & .16 & .03 & .21 & .05 & .10 & .02 \\
\hline G & .08 & .03 & .18 & .03 & .12 & .03 & .07 & .02 & .13 & .03 & .10 & .02 \\
\hline \multicolumn{13}{|l|}{ Divided } \\
\hline Old & .56 & .05 & .27 & .04 & .13 & .03 & .48 & .04 & .36 & .05 & .18 & .03 \\
\hline $\mathrm{R}$ & .34 & .04 & .11 & .03 & .02 & .01 & .31 & .05 & .19 & .04 & .07 & .02 \\
\hline $\mathrm{K}$ & .22 & .04 & .17 & .03 & .11 & .03 & .17 & .03 & .17 & .04 & .10 & .02 \\
\hline G & .15 & .03 & .18 & .03 & .12 & .03 & .06 & .02 & .11 & .03 & .10 & .02 \\
\hline
\end{tabular}

Note-R, remember; K, know; G, guess. 
Table 5

Signal Detection Measures of Discriminability $\left(d^{\prime}\right)$ and

Bias $(C)$ for Overall Studied Items and Lures in Experiment 3

\begin{tabular}{|c|c|c|c|c|c|c|c|c|}
\hline \multirow{4}{*}{$\begin{array}{c}\text { Study } \\
\text { Condition }\end{array}$} & \multicolumn{8}{|c|}{ Test Condition } \\
\hline & \multicolumn{4}{|c|}{ Full Attention } & \multicolumn{4}{|c|}{ Divided Attention } \\
\hline & \multicolumn{2}{|c|}{$d^{\prime}$} & \multicolumn{2}{|c|}{ C } & \multicolumn{2}{|c|}{$d^{\prime}$} & \multicolumn{2}{|c|}{$C$} \\
\hline & Studied & Lures & Studied & Lures & Studied & Lures & Studied & Lures \\
\hline \multicolumn{9}{|c|}{ DRM List } \\
\hline Full & 2.06 & 0.98 & 0.23 & 0.77 & 1.63 & 0.61 & 0.23 & 0.77 \\
\hline Divided & 0.91 & 0.42 & 0.80 & 1.05 & 0.89 & 0.69 & 0.63 & 0.73 \\
\hline \multicolumn{9}{|c|}{ Categorized Lists } \\
\hline Full & 1.75 & 1.28 & 0.36 & 0.60 & 1.42 & 0.94 & 0.31 & 0.55 \\
\hline Divided & 1.39 & 0.62 & 0.54 & 0.93 & 0.98 & 0.66 & 0.53 & 0.69 \\
\hline
\end{tabular}

$\left[F(1,48)=18.45, M S_{\mathrm{e}}=0.09\right]$, whereby participants were more willing to call items old when attention was divided at study. In a similar manner to Experiment 2, FA at test produced more conservative responses for critical lures $\left[F(1,48)=7.61, M S_{\mathrm{e}}=1.46\right]$. The main effect of list type was not significant $(F<1)$. The only significant interaction occurred between attention at study and test $\left[F(1,48)=9.02, M S_{\mathrm{e}}=0.09\right]$. Analysis of the simple main effects indicated that DA at study produced more liberal responses when words were retrieved in FA $[F(1,48)=$ $\left.23.09, M S_{\mathrm{e}}=0.10\right]$, than when words were retrieved in DA $(F<1)$. Measures of discriminability and criterion bias from Experiment 3 generally support those found in Experiments 1 and 2.

$R$ and $K$ responses. Correct $\mathrm{R}$ responses significantly decreased with DA at study $\left[F(1,48)=78.67, M S_{\mathrm{e}}=\right.$ 2.99]. The main effects of attention at test and list type were not significant (both $F \mathrm{~s}<1$ ). Interactions were significant between attention at study $\times$ test $[F(1,48)=$ $\left.4.45, M S_{\mathrm{e}}=1.54\right]$ and attention at study $\times$ test $\times$ list type $\left[\mathrm{F}(1,48)=9.13, M S_{\mathrm{e}}=1.54\right]$. To interpret the three-way interaction, we conducted separate 2 (attention at study) $\times$ 2 (attention at test) ANOVAs for each list type. For category words, DA at study reduced correct $\mathrm{R}$ responses $\left[F(1,24)=19.28, M S_{\mathrm{e}}=2.54\right]$. There was no significant effect of DA at test $(F<1)$ and no interaction $(F<1)$. For DRM words, DA at study also significantly reduced correct $\mathrm{R}$ responses $\left[F(1,24)=62.74, M S_{\mathrm{e}}=3.44\right]$, with no effect of DA at test; however, there was a significant study $\times$ test interaction $\left[F(1,24)=12.00, M S_{\mathrm{e}}=1.69\right]$. As is evident from the pattern of means, with FA at study, $\mathrm{DA}$ at test significantly reduced correct $\mathrm{R}$ responses $\left[F(1,24)=5.46, M S_{\mathrm{e}}=2.48\right]$, but when attention was divided at study, DA at test did not reduce performance $[F(1,24)=3.2, p=.09]$.

Analysis of $\mathrm{R}$ responses to critical lures revealed a significant main effect of DA at study $[F(1,48)=20.12$, $\left.M S_{\mathrm{e}}=1.32\right]$, whereby DA reduced false $\mathrm{R}$ responses. In contrast, DA at test increased false $\mathrm{R}$ responses to critical lures $\left[F(1,48)=11.40, M S_{\mathrm{e}}=1.23\right]$. There was no main effect of list type. These results were qualified by significant attention at study $\times$ test $\left[F(1,48)=8.19, M S_{\mathrm{e}}=\right.$ 1.47] and attention at study $\times$ test $\times$ list type $[F(1,48)=$ 6.85 $\left.M S_{\mathrm{e}}=1.47\right]$ interactions. The three-way interaction was analyzed further in separate 2 (attention at study) $\times$
2 (attention at test) ANOVAs for categorized and DRM list types. For category words, DA at study reduced R responses to critical lures $\left[F(1,24)=9.75, M S_{\mathrm{e}}=1.48\right]$, whereas DA at test increased $\mathrm{R}$ responses to critical lures $\left[F(1,24)=6.04, M S_{\mathrm{e}}=1.30\right]$. There was no interaction between the two. The main effects for DRM words were similar: DA at test increased $\mathrm{R}$ responses to critical lures $\left[F(1,24)=5.36, M S_{\mathrm{e}}=1.17\right]$ whereas DA at study reduced $\mathrm{R}$ responses to critical lures $[F(1,24)=10.50$, $\left.M S_{\mathrm{e}}=1.67\right]$; however, the interaction was significant $\left[F(1,24)=6.04, M S_{\mathrm{e}}=1.66\right]$. It is evident from the pattern of means that with DA at study, DA at test increased R responses to critical lures $\left[F(1,24)=19.90, M S_{\mathrm{e}}=1.16\right]$. However, with FA at study, DA at test had no effect on critical lures $(F<1)$. Finally, false $\mathrm{R}$ responses to unrelated items increased with DA at test $[F(1,48)=8.76$, $\left.M S_{\mathrm{e}}=1.17\right]$.

Analysis of $\mathrm{K}$ responses to correct items revealed a marginally significant main effect of DA at test $[F(1,48)=$ $\left.3.60, M S_{\mathrm{e}}=0.81, p=.06\right]$, whereby DA decreased $\mathrm{K}$ responses. The main effects of attention at study and list type were not significant $(F<1)$. Similar analysis of $\mathrm{K}$ responses to critical lures revealed only a marginally significant effect of DA at test $\left[F(1,48)=3.38, M S_{\mathrm{e}}=1.52\right.$, $p=.07]$, with DA reducing $\mathrm{K}$ responses. The main effects of DA at study and list type (both $F \mathrm{~s}<2$ ) and the interactions for these effects were not significant. False $\mathrm{K}$ responses to unrelated lures were low, but were made more often to category than to DRM words $[F(1,48)=$ $\left.4.74, M S_{\mathrm{e}}=2.89\right]$.

Secondary task performance. Performance on the secondary task was measured once at a baseline rate and again during encoding and retrieval. Participants' number sequences were measured for randomness using the RNG score developed by Evans (1978). This measure showed that generation was less random when performed at encoding $(\mathrm{RNG}=.28)$ and retrieval $(\mathrm{RNG}=.23)$ than when performed alone at baseline $(\mathrm{RNG}=.16)$. This clearly demonstrates that performing two concurrent tasks had negative effects not only on encoding and retrieval, but also on the secondary task itself. However, the RNG scores during all phases were at an acceptable level of randomness.

To summarize the results from Experiment 3, manipulating DA at both study and test showed similar main 
effects to those of Experiments 1 and 2, but a number of interactions between DA at study, DA at test, and list type warrant further explanation. For correct overall recognition, DA at study significantly reduced recognition accuracy only for DRM words; however, analysis of discriminability and response bias indicate that effects of DA at study are similar for both DRM and categorized lists. With DA at study, DA at test increased false responses to critical lures. This interaction was expected, since DA at study already reduces false recognition; the effect of DA at test therefore becomes more apparent. In a similar way to Experiments 1 and 2, DA at study reduced false $\mathrm{R}$ responses to critical lures and DA at test increased false $\mathrm{R}$ responses. Closer analysis revealed that for DRM words, critical lures increased only when attention was divided at study. However, the interactions found for the DRM lists should be treated with a certain degree of caution. The effect of DA at both study and test resulted in very low overall means, which may have resulted in these inconsistent findings.

\section{GENERAL DISCUSSION}

The aim of the present study was to investigate the effects of divided attention at study and test on the memory illusions created by DRM and categorized lists. The main findings show that DA exerted parallel effects on the false $\mathrm{R}$ responses produced by both types of list. Experiment 1 confirmed previous findings that DA at study reduces correct and false $\mathrm{R}$ responses produced by both DRM lists (Dewhurst et al., 2007) and categorized lists (Dewhurst et al., 2005). In contrast to the effects of DA at study, the findings from Experiment 2 indicate that DA at test increased false $\mathrm{R}$ responses for both types of list. Finally, Experiment 3 tested DA at both study and test. Results confirmed the findings from Experiments 1 and 2, although additional selective interactions were reported for DRM word lists.

These findings indicate that DA at both study and test exerts parallel effects on DRM and categorized lists. These views are inconsistent with those of Smith et al. (2002), who argued that false memories produced by the DRM procedure are the result of associations made at encoding, whereas false memories produced by the category repetition procedure are a result of associations made at retrieval. Smith et al. found indirect priming effects with DRM lists, whereby participants frequently completed word stems with critical lures but not with categorized word lists. They argued that this occurred because DRM items have greater backward-associative strength than do category exemplars; in addition, manipulation of test instructions on a word stem completion task only affected categorized lists. Smith et al. concluded from this that the false memories caused by category repetition were the result of associative processes at retrieval.

It is possible that the dissociations between DRM and categorized lists reported in Smith et al.'s (2002) study are due to differences in the associative structures of DRM and categorized lists. Park, Shobe, and Kihlstrom (2005) emphasized the importance of an associative link in false recognition, arguing that false recollection occurs as long as the associations are coordinate-linking items at the same level - rather than subordinate - linking items at different levels of organization. In a similar vein, Dewhurst et al. (2007) suggest that the DRM illusion and priming in a stem completion task rely on coordinate or item-to-item associations. In contrast, memory illusions produced in the category repetition procedure rely on superordinateto-item associations, whereby unstudied category exemplars are generated in response to the category label rather than to other category members. If this is the case, categorized lists should produce false memories based on superordinate-to-item associations made at encoding, even though priming effects are low because of the relatively weak item-to-item associations.

The simultaneous reduction in correct and false R responses for DRM and categorized lists in Experiment 1 is likely to be a result of a reduction in these item-to-item or superordinate-to-item associations at study. Dewhurst et al. (2005) suggested that the reduction in correct and false $\mathrm{R}$ responses occurs because both types of response depend on the activation of semantic information at encoding. For DRM lists, dividing attention prevents participants from generating semantic associations to item presented at study, thereby inhibiting the processes that support both correct and false R responses. Previous studies have demonstrated the reliance of both correct and false $\mathrm{R}$ responses on semantic associations at study. For example, correct $\mathrm{R}$ responses are enhanced by deep rather than shallow levels of processing (Gardiner, 1988) and are reduced by divided attention (Gardiner \& Parkin, 1990). False R responses are also enhanced by deep levels of processing that facilitate semantic association (Toglia, Neuschatz, \& Goodwin, 1999) and explicit instructions to generate associations at study (Dewhurst et al., 2005). As Dewhurst et al. (2005) suggested, increased semantic processing at encoding both facilitates correct recognition and increases the activation of critical lures. Reducing semantic processing by dividing attention leads to the simultaneous reduction in correct and false $\mathrm{R}$ responses. In contrast, for categorized lists the reduction in correct and false $\mathrm{R}$ responses is due to an increase in the difficulty in extracting or retaining categorical information about the study list. As a result, divided attention at study compromises the ability to generate associations to taxonomic categories rather than associations to specific items. It is, therefore, possible that, whereas DA at study reduces R responses for both DRM and categorized lists, the underlying processes that are disrupted by DA differ across the two types of list.

Experiment 2 investigated the effects of DA at retrieval on false recognition, using DRM and categorized lists. The rationale for investigating the effects of DA at retrieval was based on the findings from Smith et al. (2002) that retrieval processes influence false memories produced by categorized lists but not by DRM lists. Although little research has been conducted to investigate the effects of DA at retrieval in false memory, research has shown that retrieval processes can be disrupted by attentionally demanding tasks (see Fernandes \& Moscovitch, 2000, 2002; Hicks \& Marsh 2000). More recently, Knott and Dewhurst 
(2007) found dissociable effects of DA at test on R and $\mathrm{K}$ responses. Although Knott and Dewhurst did not use DRM or categorized lists, DA at test reduced correct $\mathrm{K}$ but not correct $\mathrm{R}$ responses, and increased false $\mathrm{R}$ but not false $\mathrm{K}$ responses. The effects of DA on correct and false $\mathrm{R}$ and $\mathrm{K}$ responses in the present study confirm these findings. For correct recognition, Knott and Dewhurst argued that $\mathrm{K}$ responses rely on postretrieval decisions disrupted by a secondary task, whereas $\mathrm{R}$ responses rely on relatively automatic processes; if an item cues contextual details, they suggested, an R response can be made immediately. However, if no contextual detail is forthcoming, additional postretrieval processing is needed to decide whether the level of familiarity experienced is sufficient to identify the item as old. These additional retrieval decisions require that the item be maintained for longer, thereby competing for resources with the secondary task (see Knott \& Dewhurst, 2007, for further discussion). These findings do not support the generally accepted assumption that remembering and knowing reflect recollection and familiarity processes, respectively (Yonelinas, 2002). Recollection is generally considered to reflect slow, controlled processing, whereas familiarity reflects rapid, automatic processing. There is further evidence, however, to support the findings by Knott and Dewhurst. For example, Dewhurst, Holmes, Brandt, and Dean (2006) found that response times for $\mathrm{R}$ responses were shorter than those for K responses (see also Dewhurst \& Conway, 1994; Gallo, Donaldson, \& Dolan, 2002).

Experiment 2 also showed that DA at retrieval increased false $\mathrm{R}$ responses. This increase in false $\mathrm{R}$ responses can be explained by the source monitoring component of the activation monitoring framework, whereby false memories occur due to a failure to distinguish between studied and self-generated items (Roediger \& McDermott, 1995). Source-monitoring errors occur (1) when memories lack sufficient discriminating information or (2) when potentially accurate source information is retrievable but is ignored in favor of more easily accessible, but less diagnostic, information (Mather, Henkel, \& Johnson, 1997). Johnson et al. (1993) distinguished between automatic and controlled source-monitoring decisions. They argued that automatic source-monitoring decisions are made, rapidly and automatically, on the basis of perceptual details or matches to schemas or templates. Individuals therefore identify the source of memories without any awareness of the decision processes used. In contrast, controlled source monitoring requires more strategic processing, incorporating slower decisions that require the retrieval of additional information and reasoning. Johnson et al. suggested that controlled source judgments are subject to greater disruption than are automatic judgments. On the basis of this assumption, the increase in false $\mathrm{R}$ responses in the present study can be seen as a result of errors in making controlled source-monitoring decisions. Without disruption, controlled and automatic monitoring processes work together to reduce recognition errors; therefore, more controlled/ systematic processes can monitor memories that would otherwise be readily accepted by less stringent automatic monitoring decisions (Johnson, 1988, 1991). The DA task increased the difficulty of using source information strategically to evaluate whether an item was studied or generated. Decisions were therefore based more on automatic source monitoring processes that rely on perceptual attributes, thereby increasing false $\mathrm{R}$ responses. Correct $\mathrm{R}$ responses are based on automatic processes that rely on perceptual attributes, and are therefore not affected by DA at test.

To summarize: The findings from the present study show that false recognition is influenced by divided attention at both study and test. When attention was divided at encoding, false $\mathrm{R}$ responses decreased because the generation of associations was inhibited. These associations are likely to be item-to-item in the case of DRM lists and superordinate-to-item in the case of categorized lists. When attention was divided at retrieval, false $\mathrm{R}$ responses increased due to interference with controlled source monitoring decisions. In contrast to the views of Smith et al. (2002), DA produced similar patterns in DRM and categorized lists. These findings indicate that false recognition caused by both the DRM and category repetition procedures can be explained within the activation monitoring framework proposed by Roediger and McDermott (1995). False recognition is reduced when divided attention prevents the generation of associates at study and increased when divided attention interferes with source monitoring processes at test.

\section{AUTHOR NOTE}

This research was conducted as part of L.M.K.'s PhD. L.M.K. was supported by a teaching studentship awarded by the Department of Psychology at Lancaster University. Correspondence concerning this article should be addressed to L. M. Knott, Department of Psychology, Lancaster University, Lancaster LA1 4YF, England (e-mail: 1.cooper1@ lancaster.ac.uk).

\section{REFERENCES}

Baddeley, A. D., Emslie, H., Kolodny, J., \& Duncan, J. (1998). Random generation and the executive control of memory. Quarterly Journal of Experimental Psychology, 51A, 819-852.

Brewer, J. B., Zhao, Z., Desmond, J. E., Glover, G. H., \& GabriELI, J. D. E. (1998). Making memories: Brain activity that predicts how well visual experience will be remembered. Science, 281, 11851187.

Craik, F. I. M., Govoni, R., Naveh-Benjamin, M., \& Anderson, N. D. (1996). The effects of divided attention on encoding and retrieval processes in human memory. Journal of Experimental Psychology: General, 125,159-180.

DeESE, J. (1959). On the prediction of occurrence of particular verbal intrusions in immediate recall. Journal of Experimental Psychology, $\mathbf{5 8}, 17-22$.

Dewhurst, S. A., \& ANDERson, S. J. (1999). Effects of exact and category repetition in true and false recognition memory. Memory \& Cognition, 27, 665-673.

Dewhurst, S. A., Barry, C., \& Holmes, S. J. (2005). Exploring the false recognition of category exemplars: Effects of divided attention and explicit generation. European Journal of Cognitive Psychology, 17, 803-819.

Dewhurst, S. A., Barry, C., Swannell, E. R., Holmes, S. J., \& Bathurst, G. L. (2007). The effects of divided attention on false memory depend on how memory is tested. Memory \& Cognition, 35, 660-667.

Dewhurst, S. A., \& Conway, M. A. (1994). Pictures, images, and recollective experience. Journal of Experimental Psychology: Learning, Memory, \& Cognition, 20, 1088-1098. 
Dewhurst, S. A., \& Farrand, P. (2004). Investigating the phenomenological characteristics of false recognition for categorised words. European Journal of Cognitive Psychology, 16, 403-416.

Dewhurst, S. A., Holmes, S. J., Brandt, K. R., \& Dean, G. M. (2006). Measuring the speed of the conscious components of recognition memory: Remembering is faster than knowing, Consciousness \& Cognition, 15, 147-162.

Eldridge, L. L., Sarfatti, S., \& Knowlton, B. J. (2002). The effect of testing procedure on remember-know judgments. Psychonomic Bulletin \& Review, 9, 139-145.

Evans, F. J. (1978). Monitoring attention deployment by random number generation: An index to measure subjective randomness. Bulletin of the Psychonomic Society, 12, 35-28.

Fernandes, M. A., \& Moscovitch, M. (2000). Divided attention and memory: Evidence of substantial interference effects at retrieval and encoding. Journal of Experimental Psychology: General, 129, 155-176.

Fernandes, M. A., \& Moscovitch, M. (2002). Factors modulating the effect of divided attention during retrieval of words. Memory \& Cognition, 30, 731-744.

Gallo, D. A., Donaldson, D. I., \& Dolan, P. O. (2002, November). Waiting for recollection, fast recollection, or illusory recollection: What do response latencies tell us? Paper presented at the annual meeting of the Psychonomic Society, Kansas City, MO.

GARDINER, J. M. (1988). Functional aspects of recollective experience. Memory \& Cognition, 16, 309-313.

Gardiner, J. M., \& Conway, M. A. (1999). Levels of awareness and varieties of experience. In B. H. Challis \& B. M. Velichkovsky (Eds.), Stratification in cognition and consciousness (pp. 237-254). Amsterdam: John Benjamins.

Gardiner, J. M., JaVA, R. I., \& Richardson-Klavehn, A. (1996). How level of processing really influences awareness in recognition memory. Canadian Journal of Experimental Psychology, 50, 114-122.

Gardiner, J. M., Konstantinou, I., Karayianni, I., \& GregG, V. H. (2005). Memory awareness following speeded compared with unspeeded picture recognition. Experimental Psychology, 52, 140-149.

Gardiner, J. M., \& PARKIN, A. J. (1990). Attention and recollective experience in recognition memory. Memory \& Cognition, 18, 579-583.

GaRdiner, J. M., RAMPONI, C., \& RichaRdSON-KLAVEhN, A. (2002). Recognition memory and decision processes: A meta-analysis of remember, know, and guess responses. Memory, 10, 83-98.

Heit, E., BrockdorfF, N., \& LAmberTs, K. (2004). Strategic processes in false recognition memory. Psychonomic Bulletin \& Review, 11, 380-386.

HiCKS, J. L., \& Marsh, R. L. (1999). Remember-know judgments can depend on how memory is tested. Psychonomic Bulletin \& Review, 6, $117-122$.

HiCKs, J. L., \& MARSH, R. L. (2000). Toward specifying the attentional demands of recognition memory. Journal of Experimental Psychology: Learning, Memory, \& Cognition, 26, 1483-1498.

Johnson, M. K. (1988). Discriminating the origin of information. In T. F. Oltmanns \& B. A. Maher (Eds.), Delusional beliefs (pp. 34-65). Oxford: Wiley.

Johnson, M. K. (1991). Reality monitoring: Evidence from confabulation in organic brain disease patients. In G. P. Prigatano \& D. L. Schacter (Eds.), Awareness of deficit after brain injury: Clinical and theoretical issues (pp. 176-197). New York: Oxford University Press.
Johnson, M. K., Hashtroudi, S., \& Lindsay, D. S. (1993). Source monitoring. Psychological Bulletin, 114, 3-28.

KiRKPATRICK, E. A. (1894). An experimental study of memory. Psychological Review, 1, 602-609.

Knott, L. M., \& Dewhurst, S. A. (2007). Divided attention at retrieval disrupts knowing but not remembering. Memory, 15, 664-674.

Mather, M., Henkel, L. A., \& Johnson, M. K. (1997). Evaluating characteristics of false memories: Remember/know judgments and memory characteristics questionnaires compared. Memory \& Cognition, 25, 826-837.

Park, L., Shobe, K. K., \& Kinlstrom, J. F. (2005). Associative and categorical relations in the associative memory illusion. Psychological Science, 16, 792-797.

Pierce, B. H., Gallo, D. A., Weiss, J. A., \& Schacter, D. L. (2005). The modality effect in false recognition: Evidence for test-based monitoring. Memory \& Cognition, 33, 1407-1413.

RoEdiger, H. L., III, \& McDermotT, K. B. (1995). Creating false memories: Remembering words not presented in lists. Journal of Experimental Psychology: Learning, Memory, \& Cognition, 21, 803-814.

Seamon, J. G., Luo, C. R., Schlegel, S. E., Greene, S. E., \& GoldenBERG, A. B. (2000). False memory for categorized pictures and words: The category associates procedure for studying memory errors in children and adults. Journal of Memory \& Language, 42, 120-146.

Smith, S. M., Gerkens, D. R., Pierce, B. H., \& ChoI, H. (2002). The roles of associative responses at study and semantically guided recollection at test in false memory: The Kirkpatrick and Deese hypothesis. Journal of Memory \& Language, 47, 436-447.

SnOdgrass, J. G., \& Corwin, J. (1988). Pragmatics of measuring recognition memory: Applications to dementia and amnesia. Journal of Experimental Psychology: General, 117, 34-50.

Stadler, M. A., Roediger, H. L., III, \& McDermott, K. B. (1999). Norms for word lists that create false memories. Memory \& Cognition, 27, 494-500.

Toglia, M. P., Neuschatz, J. S., \& Goodwin, K. A. (1999). Recall accuracy and illusory memories: When more is less. Memory, 7, 233256.

TowsE, J. N., \& NeIL, D. (1998). Analyzing human random generation behavior: A review of methods used and a computer program for describing performance. Behavior Research Methods, Instruments, \& Computers, 30, 583-591.

Tulving, E. (1985). Memory and consciousness. Canadian Psychology, 26, 1-12.

UNDERWOOD, B. J. (1965). False recognition produced by implicit verbal responses. Journal of Experimental Psychology, 70, 122-129.

Van Overschelde, J. P., Rawson, K. A., \& Dunlosky, J. (2004). Category norms: An updated and expanded version of the Battig and Montague (1969) norms. Journal of Memory \& Language, 50, 289-335.

Yonelinas, A. P. (2002). The nature of recollection and familiarity: A review of 30 years of research. Journal of Memory \& Language, 46, 441-517.

Yonelinas, A. P., \& JACOBY, L. L. (1995). The relation between remembering and knowing as bases for recognition: Effects of size congruency. Journal of Memory \& Language, 34, 622-643.

(Manuscript received June 20, 2006; revision accepted for publication April 27, 2007.) 